\title{
Crianças e Adolescentes Portadores de Anemia Falciforme e Profissionais de Saúde: Submissão Ou Autonomia?
}

\author{
Sousa, Eulange de; Medeiros, Marcelo \\ Ufg, SMS/Goiania, Fapeg - eulange@gmail.com
}

\begin{abstract}
Introdução: Anemia falciforme é uma doença hereditária considerada um problema de saúde pública no Brasil. Estima-se que existem no Brasil mais de 2 milhões de pessoas afetados por alguma forma desta anemia com uma ocorrência de 3.500 novos caso por ano. As doenças falciformes provocam na maioria dos órgãos e aparelhos um grande leque de complicações clínicas que podem comprometer diretamente a função de órgãos vitais como infecções, complicações cardiorrespiratórias, insuficiência renal e acidentes vasculares cerebrais. em outros casos seus portadores tem complicações como ulceras nas pernas, retinopatia, necrose ósseas, cálculos de vesícula. um aspecto marcante na patologia é a crise dolorosa em extremidades, região lombar, abdome ou tórax. Nestes casos a intervenção da equipe de saúde e imprescindível para aliviá-la e, nestes momentos, a capacidade do profissional de saúde para promover intervenções eficazes é fundamental. a capacidade de intervenção não está relacionada apenas ao conhecimento técnicocientífico sobre a doença, mas também à capacidade que a equipe de saúde tem para avaliar a intensidade da dor de que o portador se queixa. Historicamente observamos diversas posturas na relação entre profissionais de saúde e doentes sendo que na maioria das vezes aos doentes é reservado o lugar de pacientes, ou seja aqueles que padecem ou vão padecer e outras posturas que adotam como pressuposto que a relação a ser estabelecida deve ser a de que os doentes são sujeitos e tem autonomia em suas ações. Objetivos: Analisar as relações estabelecidas entre crianças e adolescentes portadores de anemia falciforme com os profissionais no âmbito dos serviços de saúde, tanto na visão das equipes de saúde quanto dos próprios portadores. Métodos: Pesquisa social estratégica qualitativa, tendo como local de estudo um hospital de ensino federal . Os dados foram obtidos por meio de entrevistas semi-estruturadas e a análise está sendo realizada com a técnica de análise de conteúdo na perspectiva de Laurence Bardin. Resultados: Foram realizadas 8 entrevistas com profissionais de saúde e $8 \mathrm{com}$ crianças e adolescentes. o trabalho encontra-se em fase de análise dos dados e inicialmente percebe-se que o papel destinado às crianças é diferente do dos adolescentes no qual a criança tem uma menor participação em relação a relatos de queixas e cotidiano em relação à doença. Outra questão que aparece em todas as entrevistas com os profissionais da equipe é a preocupação com o fato de que muitas vezes os que prestam assistência na emergência ou em internações não consideram adequadamente as queixas de dor apresentadas pelas crianças e adolescentes, causando-Ihes muito sofrimento. Conclusões: o estudo realizado poderá subsidiar a formação de profissionais de saúde no sentido de considerar crianças e adolescentes como protagonistas em seu processo saúde-doença e influenciar na assistência aos períodos de crise álgica e outras complicações da doença.
\end{abstract}

Sousa, Eulange de; Medeiros, Marcelo. Crianças e Adolescentes Portadores de Anemia Falciforme e Profissionais de Saúde: Submissão Ou Autonomia?. In: Anais do Congresso Internacional de Humanidades \& Humanização em Saúde [= Blucher Medical Proceedings, num.2, vol.1]. São Paulo: Editora Blucher, 2014. ISSN 2357-7282 DOI 10.5151/medpro-cihhs-10309 